\title{
In vivo efficiency of antimicrobial inorganic bone grafts in osteomyelitis treatments
}

G. Mestres ${ }^{1, \mathscr{H}}$, M.A. Fernandez-Yague ${ }^{2,3, \S, \mathscr{H}}$, D. Pastorino ${ }^{2,3}$, E.B. Montufar ${ }^{4}$, C. Canal ${ }^{2,3}$, M.C. Manzanares-Céspedes ${ }^{5,6}$ and M.P. Ginebra ${ }^{2,3,7, *}$

${ }^{1}$ Department of Engineering Sciences, Science for Life Laboratory, Uppsala University, Box 534, 751 21 Uppsala, Sweden

${ }^{2}$ Biomaterials, Biomechanics and Tissue Engineering Group, Dpt. Materials Science and Metallurgy, Universitat Politècnica de Catalunya (UPC), Av. Eduard Maristany 10-14, 08019 Barcelona, Spain

${ }^{3}$ Research Centre in Multiscale Science and Engineering, UPC, Barcelona, Spain

${ }^{4}$ CEITEC - Central European Institute of Technology, Brno University of Technology, Brno, Czech Republic ${ }^{5}$ Human Anatomy and Embryology Unit. University of Barcelona, Faculty of Medicine and Health Sciences, Barcelona, Spain

${ }^{6}$ Growth factors and cellular differenciation (Bellvitge Biomedical Research Institute, IDIBELL) L'Hospitalet de Llobregat, Barcelona, Spain

${ }^{7}$ Institute of Bioengineering of Catalonia (IBEC), Baldiri i Reixach 10-12, 08028 Barcelona, Spain

§Present address: Department of Mechanical and Biomedical Engineering, National University of Ireland, Galway, Ireland

If Both authors contributed equally to this work

* Corresponding author: Maria-Pau Ginebra

Postal address: Biomaterials, Biomechanics and Tissue Engineering Group, Dpt. Materials Science and Metallurgy, Universitat Politècnica de Catalunya (UPC), Av. Eduard Maristany 10-14, 08019 Barcelona, Spain E-mail: maria.pau.ginebra@upc.edu

\begin{abstract}
The purpose of the present work was to evaluate in vivo different antimicrobial therapies to eradicate osteomyelitis created in the femoral head of New Zealand rabbits. Five phosphate-based cements were evaluated: calcium phosphate cements (CPC) and calcium phosphate foams (CPF), both in their pristine form and loaded with doxycycline hyclate, and an intrinsic antimicrobial magnesium phosphate cement (MPC; not loaded with an antibiotic). The cements were implanted in a bone previously infected with Staphylococcus aureus to discern the effects of the type of antibiotic administration (systemic vs. local), porosity (microporosity, i.e. $<5 \mu \mathrm{m}$ vs. macroporosity, i.e. $>5 \mu \mathrm{m}$ ) and type of antimicrobial mechanism (release of antibiotic vs. intrinsic antimicrobial activity) on the improvement of the health state of the infected animals. A new method was developed, with a more comprehensive composite score that integrates 5 parameters of bone infection, 4 parameters of bone structural integrity and 4 parameters of bone regeneration. This method was used to evaluate the health state of the infected animals, both before and after osteomyelitis treatment. The results show that the composite score allows to discern statistically significant differences between treatments that individual evaluations were not able to identify. Despite none of the therapies completely eradicated the infection, it was observed that
\end{abstract}


macroporous materials ( $\mathrm{CPF}$ and $\mathrm{CPFd}$, the latter loaded with doxycycline hyclate) and intrinsic antimicrobial MPC allowed a better containment of the osteomyelitis. This study provides novel insights to understand the effect of different antimicrobial therapies in vivo, and a promising comprehensive methodology to evaluate the health state of the animals was developed. We expect that the implementation of such methodology could improve the criteria to select a proper antimicrobial therapy.

Keywords: Osteomyelitis, calcium phosphate cements, calcium phosphate foams, magnesium phosphate cements, drug delivery, in vivo

\section{Graphical abstract}

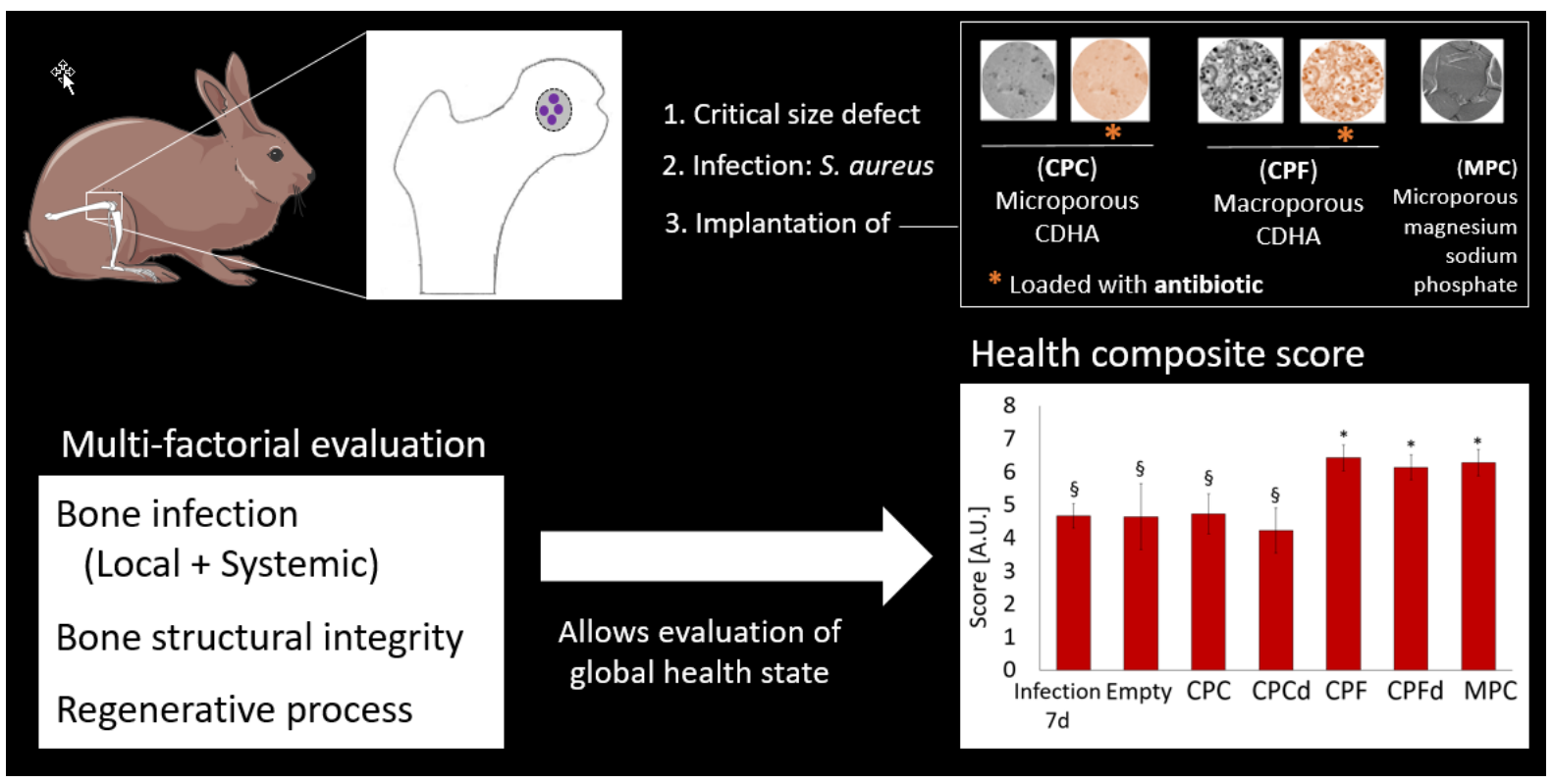

\section{Highlights}

- Antibiotic-loaded calcium phosphates cements were used for osteomyelitis treatment

- Macroporous calcium phosphates showed better performance in vivo than microporous ones

- Microporous magnesium phosphates cements had intrinsic antimicrobial activity in vivo

- A composite score provides a comprehensive evaluation of the animals' health state 


\section{Introduction}

Osteomyelitis, the infection of bone tissue or bone marrow by bacteria or fungi, can arise from the migration of a pathogen either present in the blood stream or in the bone through an open fracture or during a surgery ${ }^{1-3}$. Despite the improvement on prophylaxis, surgical techniques, postoperative care and availability of new antibiotics leading to superior treatment efficacies, perioperative osteomyelitis remains as one of the most serious complications in orthopaedics and traumatology $y^{4,5}$. In particular, surgical procedures involving open fractures, removal of bone tumours, joint replacement or treatment of a previous bone infection are susceptible to (re)infection. Among the different pathogens, Staphylococcus aureus (S. aureus) has been identified in $38 \%$ to $67 \%$ of the osteomyelitis cases diagnosed over the past decade ${ }^{6}$. Treatments against osteomyelitis traditionally consist in the systemic administration of antibiotics, which implies that only a small amount of the drug reaches the target site due to first pass effect, distribution, elimination, etc. In the case of osteomyelitis, the access of the antibiotic to the infection site is even more difficult due to the local destruction of blood vessels in the bone site. Moreover, it is well known that secondary effects can be associated to systemic drug administration. Substituting the systemic treatment with a local therapy may be a more efficient strategy, associating a lower dosage of the active principle and thus minimizing possible side effects $^{7,8}$.

The local treatment of osteomyelitis requires a carrier that releases the antimicrobial agent in a controlled manner. The most extended carrier currently used in clinics is poly(methyl methacrylate) (PMMA) $)^{9-11}$ which elute antibiotics slowly. Nonetheless, PMMA is non degradable (i.e. does not allow new bone formation) and requires a second surgery to remove it once the treatment is finished ${ }^{12,13}$. Therefore, the development of osteoconductive biomaterials that provide an adequate scaffold for new bone ingrowth and also have antimicrobial properties represents a milestone in the treatment of bone infections. Furthermore, injectable and biodegradable materials are preferable, as they can be implanted by minimally invasive surgery and avoid the second surgery needed to remove non-degradable implants ${ }^{11}$, thus minimizing the risk of (re)infection and reducing patient morbidity.

Calcium phosphate cements (CPCs) are a large family of injectable pastes that are able to harden after being implanted in the body. After hardening, CPCs mimic the structure and composition of the mineral component of bone, providing them with excellent biocompatibility, bioactivity and osteoconductivity ${ }^{14}$. CPCs based on alpha tricalcium phosphate ( $\alpha$-TCP) have been used in minimally invasive surgery to regenerate bone defects, both as non-macroporous ${ }^{15}$ and as macroporous materials. Macroporous CPC, also called calcium phosphate foams (CPFs) $)^{16}$, count with an interconnected network of pores larger than $5 \mu \mathrm{m}$ (macropores) over the inherent microporous structure of CPCs

(typically with sizes below $2 \mu \mathrm{m})^{17,18}$. Furthermore, CPCs and CPFs loaded with doxycycline hyclate have shown in vitro antimicrobial properties against Streptococcus sanguinis and Lactobacillus 
salivarius in vitro ${ }^{19}$. Alternative injectable cements that recently have raised interest due to their intrinsic antimicrobial properties are magnesium phosphate cements (MPCs) ${ }^{20}$. The active mechanisms of MPCs against bacteria have been ascribed to the alkaline $\mathrm{pH}$ and osmolar modifications of the local environment ${ }^{21}$. Despite the promising in vitro results of CPC, CPF and MPC to act as multifunctional biomaterials, their efficacy in vivo to simultaneously treat bone infection and their regenerative potential has not been studied yet.

In order to evaluate the antimicrobial performance of a therapy, a generally accepted procedure consists on creating an osteomyelitis condition in an animal model and, after allowing a certain infection period, apply the therapeutic treatment ${ }^{22}$. Typically, the outcome of an in vivo osteomyelitis treatment has been quantified using the Smeltzer's scale ${ }^{23}$. However, this scale is limited as it only evaluates the degree of bone destruction due to the infection and does not consider any signs of bone regeneration. To the best of authors' knowledge, a scale evaluating simultaneously the severity of infection, bone structural integrity at the infection site and signs of bone remodelling to comprehensibly assess the osteomyelitis condition is not currently available.

In this context, the aim of this work was two-fold. First, to assess the efficacy of antibiotic-loaded CPCs, CPFs and of intrinsically antibacterial MPC as therapies with the dual function of eradicating osteomyelitis and regenerating the affected bone tissue. This study was designed to understand the effects of material pore size, route of administration for antibiotic (local vs. systemic) and antimicrobial approach (local release of an antibiotic vs. material with intrinsic antimicrobial properties) on bone healing in a complex scenario of local bone infection. Second, to develop a novel multi-factorial evaluation to relate three different biological responses, i.e. extension of the infection, bone structural integrity and state of the bone regeneration process, in one global and comprehensive scale of the health state of the animal.

\section{Materials and methods}

\subsection{Materials}

Three injectable bone grafts were tested along the study: CPCs, CPFs and MPC. CPCs and CPFs were both used in their pristine form and loaded with doxycycline hyclate $(\mathrm{CPCd}$ and $\mathrm{CPFd}$, respectively). Therefore, a total of 5 different cements (CPC, CPCd, CPF, CPFd and MPC) were implanted. Table 1 provides an overview of the initial composition, product of the setting reaction, pore size distribution and type of antimicrobial activity of these materials. 
Table 1. Bone grafting materials used

\begin{tabular}{|c|c|c|c|c|c|c|c|}
\hline $\begin{array}{l}\text { Bone } \\
\text { graft }\end{array}$ & Powder phase & Liquid phase & $\begin{array}{l}\text { End product in } \\
\text { vitro }\end{array}$ & Porosity [\%] & $\begin{array}{l}\text { Pore size } \\
\text { range }[\mu \mathrm{m}]\end{array}$ & $\begin{array}{l}\text { Antimicrobial } \\
\text { approach }\end{array}$ & References \\
\hline $\mathrm{CPC}$ & \multirow{2}{*}{$\begin{array}{l}\alpha-\mathrm{TCP}+2 \quad \mathrm{wt} \% \\
\text { hydroxyapatite }\end{array}$} & Distilled water & \multirow{2}{*}{ CDHA } & \multirow{2}{*}{50} & \multirow{2}{*}{$\begin{array}{l}\text { Micro: } 0.006 \\
-0.1 \\
\text { Macro: none }\end{array}$} & $\begin{array}{l}\text { Systemic } \\
\text { doxycycline } \\
\text { hyclate }(4 \mathrm{mg} \\
/ \mathrm{kg})\end{array}$ & \multirow[t]{2}{*}{19} \\
\hline CPCd & & $\begin{array}{l}50 \mathrm{mg} / \mathrm{mL} \text { of } \\
\text { doxycycline hyclate } \\
\text { in distilled water }\end{array}$ & & & & $\begin{array}{l}\text { Local release } \\
\text { of doxycycline } \\
\text { hyclate }\end{array}$ & \\
\hline $\mathrm{CPF}$ & $\begin{array}{l}\alpha-\mathrm{TCP}+2 \mathrm{wt} \% \\
\text { hydroxyapatite }\end{array}$ & \multirow{2}{*}{$\begin{array}{l}1 \mathrm{wt} \% \text { Polysorbate } \\
80 \mathrm{in} \text { distilled water }\end{array}$} & \multirow[t]{2}{*}{ CDHA } & \multirow{2}{*}{$\begin{array}{l}\text { Total }=66 \\
\text { Macroporosity } \\
\text { (pores }>5 \mu \mathrm{m} \text { ) } \\
=32\end{array}$} & \multirow{2}{*}{$\begin{array}{l}\text { Micro: } 0.006 \\
-2 \\
\text { Macro: } 10- \\
300\end{array}$} & $\begin{array}{l}\text { Systemic } \\
\text { doxycycline } \\
\text { hyclate }(4 \mathrm{mg} \\
/ \mathrm{kg})\end{array}$ & \multirow[t]{2}{*}{17} \\
\hline CPFd & $\begin{array}{l}\alpha-\mathrm{TCP}+2 \text { wt } \% \\
\text { hydroxyapatite }+2.4 \\
\text { wt } \% \quad \text { doxycycline } \\
\text { hyclate }\end{array}$ & & & & & $\begin{array}{l}\text { Local release } \\
\text { of doxycycline } \\
\text { hyclate }\end{array}$ & \\
\hline MPC & $\begin{array}{l}\mathrm{MgO}: \mathrm{NaH}_{2} \mathrm{PO}_{4} \\
(3.8: 1 \text { molar ratio })+3 \\
\mathrm{wt} \% \text { borax }\end{array}$ & Distilled water & $\begin{array}{l}\text { Amorphous } \\
\text { magnesium } \\
\text { sodium } \\
\text { phosphate }\end{array}$ & 17 & $\begin{array}{l}\text { Micro: } 0.006 \\
-5 \\
\text { Macro: } 5- \\
70\end{array}$ & $\begin{array}{l}\text { Intrinsic } \\
\text { antimicrobial } \\
\text { properties of } \\
\text { MPC (high pH } \\
\text { and } \\
\text { osmolarity) }\end{array}$ & 20 \\
\hline
\end{tabular}

$\alpha$-TCP: $\alpha$-Tricalcium Phosphate; CDHA: Calcium Deficient Hydroxyapatite; CPC: Calcium Phosphate Cement; CPF: Calcium Phosphate Foam; MPC: Magnesium Phosphate cement

CPCs were prepared manually by mixing a powder phase with a liquid phase at a liquid to powder ratio of $0.55 \mathrm{~mL} / \mathrm{g}^{19}$. The powder phase was $\alpha$-Tricalcium Phosphate $(\alpha-\mathrm{TCP})$ with $2 \mathrm{wt} \%$ precipitated hydroxyapatite (ref. n. 7758-87-4 Merck). The liquid phase consisted either in distilled water for CPC or a $50 \mathrm{mg} / \mathrm{mL}$ aqueous solution of doxycycline hyclate (Sigma-Aldrich, doxycycline hydrochloride hemiethanolate hemihydrate, $\mathrm{C}_{22} \mathrm{H}_{24} \mathrm{~N}_{2} \mathrm{O}_{8} \cdots \mathrm{HCl} \cdots 0.5 \mathrm{H}_{2} \mathrm{O} \cdots 0.5 \mathrm{C}_{2} \mathrm{H}_{6} \mathrm{O} ; \mathrm{MW}: 1025.89$ $\mathrm{g} / \mathrm{mol}$, ref. n. D3000000) for CPCd.

CPFs were prepared by simultaneously mixing and foaming the same powder phase as CPCs and an aqueous solution of $1 \mathrm{wt} \%$ Polysorbate 80 (ref. n. 59924 Sigma-Aldrich, UK) at a liquid to powder ratio of $0.55 \mathrm{~mL} / \mathrm{g}$. The mixing and foaming of the phases was performed simultaneously inside a $60 \mathrm{ml}$ syringe using a custom-made mixer (stainless steel blade adapted to a Dremel 4000, Robert Bosch Tool Corporation) at $6000 \mathrm{rpm}$ during $30 \mathrm{~s}^{17}$. To prepare the CPFd, doxycycline hyclate powder (amount equivalent to $50 \mathrm{mg} / \mathrm{ml}$ of liquid phase) was introduced in the syringe during foaming (at second 20) to allow its homogenization and foaming ${ }^{17}$.

MPC was prepared mixing dead burnt magnesium oxide (MgO, ref. n. 1309-48-4, Merck) and sodium hydrogen phosphate $\left(\mathrm{NaH}_{2} \mathrm{PO}_{4}, 7558-80-7\right.$, Fluka) at a 3.8:1 molar ratio and $3 \mathrm{wt} \%$ of borax 
was added to retard the reaction (Fluka, ref. n. 72,000$)^{20}$. The powder was manually mixed with distilled water at a liquid to powder ratio of $0.17 \mathrm{~mL} / \mathrm{g}$ to prepare the cement paste.

To guaranty the sterility for in vivo studies, the solid components were sterilized by gamma radiation at a $25 \mathrm{KGy}$ dose and the liquid phases were sterilized by filtration through $0.22 \mu \mathrm{m}$ membranes. After mixing the solid and liquid phase, all grafts had the consistency of a workable paste and were injected using sterile $5 \mathrm{~mL}$ syringes with $2 \mathrm{~mm}$ aperture.

\subsection{Development of osteomyelitis in in vivo model}

The in vivo study was performed at the animal experimentation facility of the Universidad de Santiago de Compostela, in Lugo, (Spain) with the ethical committee authorization: AE-LU002/2012/INV.MED.02/PAT[05]/AGC2. The use and handling of the animals was performed according to the European Union Guidelines for the Care and Use of Laboratory Animals (86/609/CE). In this study 42 adult female New Zealand rabbits (16 weeks old and average weight $5 \mathrm{~kg}$ ) were used. All rabbits were quarantined three weeks prior to surgery. During the study, the animals were housed in separate cages in a climate-controlled room with free access to food and water. Before surgery, the rabbits were divided in randomized test groups of 6 rabbits each, as detailed in Figure 1.

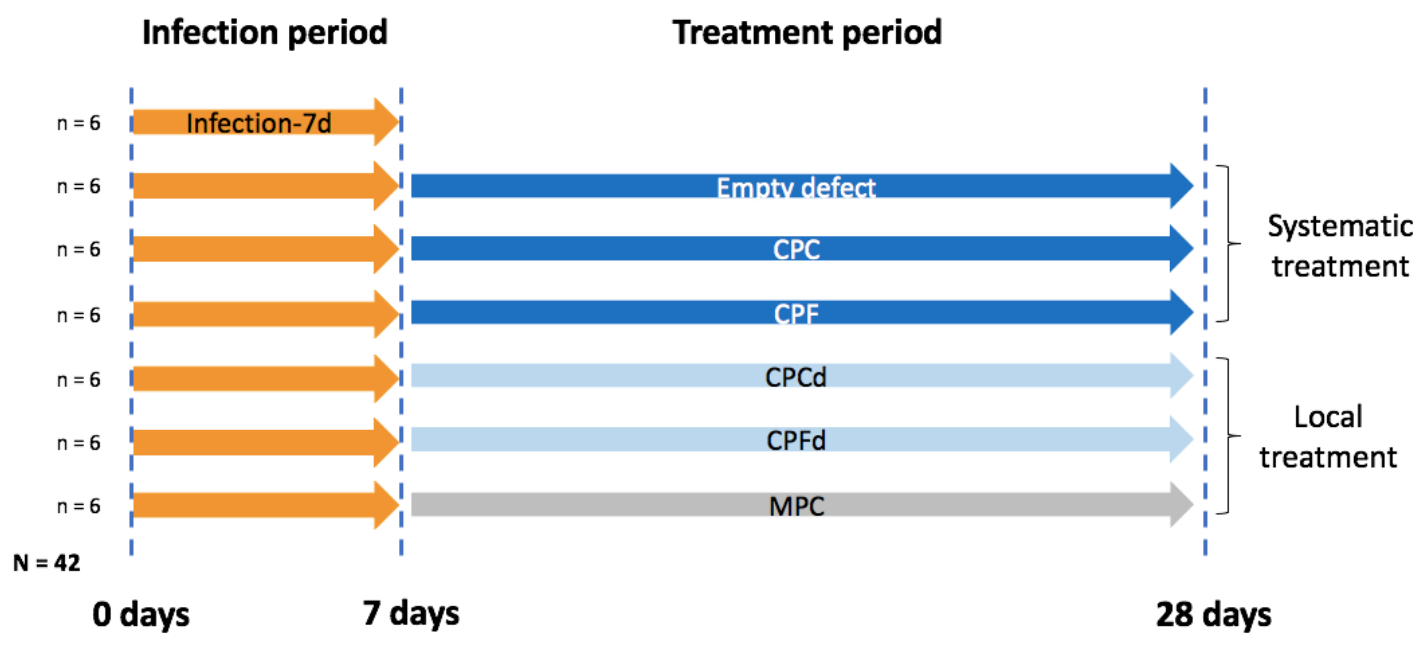

Figure 1. Design of the animal study including group nomenclature, sampling times and type of antimicrobial treatment, i.e. local (implantation of a material with antimicrobial activity) or systemic (oral administration of antibiotic in addition to the implantation of the material without antimicrobial activity).

At day 0 , the animals were anesthetized and the femoral condyle of one caudal leg, randomly selected, was exposed by a lateral longitudinal incision. A bone defect $(\varnothing=4 \mathrm{~mm}$, length $=8 \mathrm{~mm})$ was created parallel to the axis connecting the medial and lateral condyle in the distal part of the femur by trephination using constant saline irrigation to avoid thermal necrosis (Figure 2). Bacterial infection was induced with PMMA rods $(\varnothing=4 \mathrm{~mm}$, length $=8 \mathrm{~mm})$, which were previously immersed in a $S$. aureus inoculum for $16 \mathrm{~h}$ at $37^{\circ} \mathrm{C}$, washed with phosphate buffer saline (PBS), dried, stored at $-80{ }^{\circ} \mathrm{C}$ 
and used within a week. The rod was press-fit into the bone defect, the wound was cleaned thoroughly with povidone-iodine solution wipes (to prevent infection unrelated to the bone tissue) and sutured. Each animal received peri- and post-operative analgesia using buprenorphine $(0.15 \mathrm{mg} / \mathrm{Kg} \mathrm{IM}$; Buprex, RB Pharmaceuticals, Berkshire, UK) and pain control with meloxicam $(0.3 \mathrm{mg} / \mathrm{Kg}$ subcutaneous; Metacam, Boehringer Ingelheim, Barcelona, Spain). Each animal was monitored until full recovery from anaesthesia. No antibiotics were administrated to any rabbit before or after this first surgery.

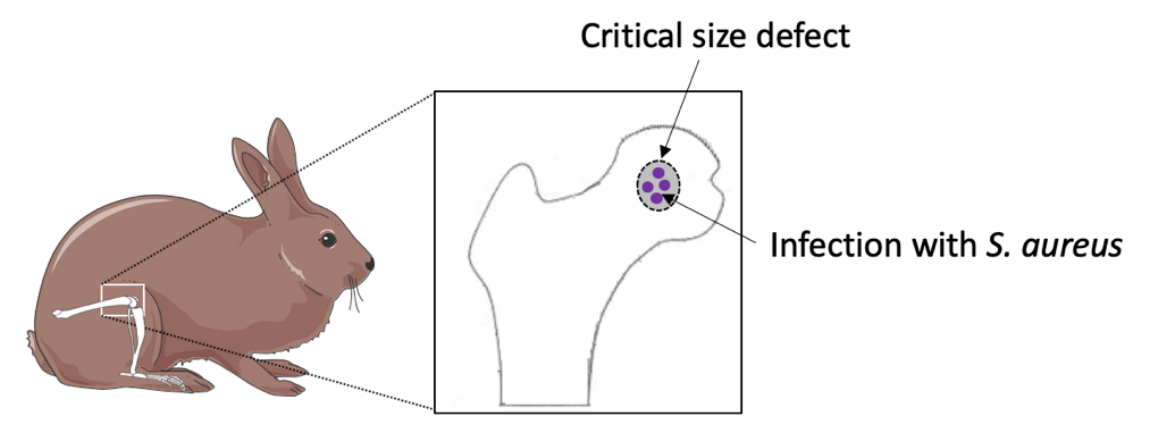

Figure 2. Sketch representing the defect performed in the rabbits' femoral condyle

At day 7 , the animals in the Infection-7d group were euthanized for evaluation while the animals in all other groups were submitted to a second surgery. The second surgery consisted on removal of the PMMA rods, pus aspiration and placement of the corresponding bone graft (except for the Empty defect group) by injection (Figure 1). No surgical debridement was performed in any case. After filling the defect, the wound was sutured and all animals were treated with postoperative analgesia and pain control. The animals within the groups Empty defect, $C P C$ and $C P F$ further received a systemic daily doxycycline hyclate dose $(4 \mathrm{mg} / \mathrm{kg})^{24}$ dissolved in drinking water. Animals within the groups $C P C d$, $C P F d$ and $M P C$ did not receive systemic antibiotic since the implanted materials should have local antimicrobial activity.

At day 28 all animals were euthanized. Both implanted and non-infected/non-implanted contralateral femurs were explanted and the surrounding soft tissues were removed.

\subsection{Systemic evaluation of the osteomyelitis state: blood test}

The systemic health state of the animals was evaluated through blood testing before surgery (day $0 ; \mathrm{n}=42$ ), at 7 days after infection (Infection-7d group; $\mathrm{n}=42$ ) and at the end of the treatment period (day 28; $n=6$ ). Blood tests were performed by Idexx Laboratories, Inc. (Barcelona, Spain) and the complete blood counts and plasma proteins were determined.

The systemic markers evaluated from the blood test were divided into non-specific response (monocyte counts) and specific response (albumin/globulin ratio). A low albumin/globulin ratio indicated the presence of an infection in the animal, since acute inflammation triggers an increment in concentration and activity of lymphocytes, which produce immune proteins such as globulins to combat 
the infection. The values of monocyte counts and albumin/globulin ratio were further normalized to a scale from 0 to 4 (according with Table 2) with the purpose to be included in the composite scale.

\subsection{Local evaluation of the osteomyelitis state}

2.4.1. Radiographic observation. The femoral condyle area was evaluated by X-ray images (Philips Super $80 \mathrm{CP}$ ). The bone density and degree of bone lesion around the implant (radiopacity) was scored by two independent experts using a scale from 0 to 4 according to Table 2 .

2.4.2. Histological analysis. After explanting and removing the soft tissues, the femurs were kept in 4 $\mathrm{v} / \mathrm{v} \%$ formaldehyde solution for 3 weeks and afterwards cut (Exakt 300, Germany) normally to the axis of the cylindrical defect to obtain $2 \mathrm{~mm}$ circular slices of it. For each femur condyle, two cuts were stained using either Masson's trichrome staining (MT) or haematoxylin - eosin (HE) staining. The contralateral femur condyles were also processed for comparative purposes.

Regarding sample preparation for MT staining, the samples were gradually dehydrated by progressive ethanol immersion. Afterwards, the ethanol was progressively replaced by PMMA resin (Tecnovit 7200 VLC, EXAKT, Germany). Samples were then UV-cured overnight (Exakt 520, Germany). The polymerized blocks were cut and polished (Exakt 400 CS, Exakt AW110, Germany) down to $30-70 \mu \mathrm{m}$ slices. MT staining was then performed according common protocols.

In contrast, for $\mathrm{HE}$ staining, the slices were decalcified using bone marrow biopsy decalcifying solution (05-M03005, Osteodec, Bio-Optica, Italy) during 3 months. Afterwards, the samples were embedded in paraffin, cut to an average thickness of $6 \mu \mathrm{m}$ (RM2145 microtome, Leica, Germany), placed on a glass coverslips and stained with HE following standard protocols.

2.4.3. Bone structural integrity evaluation. Stained samples were observed using a bright field optical microscope (AF 7000, Leica, Germany). Images of MT staining were segmented to separate red (fibrous tissue) from blue (bone/collagen) stained areas (Figure 3a). The zones of trabecular bone with collagen fiber alignment were observed with polarized light in MT stained samples (Figure 3b).

In non-implanted contralateral femurs, the femur condyle was defined as the first region of interest (ROI-1), excluding the growth plate and the cortical part of the bone when visible. In implanted samples, the area surrounding the defect (equivalent to a ring of $0.8 \mathrm{~mm}$ of thickness measured from the edge of the defect/implant) was defined as the second region of interest (ROI-2) (Figure 3c). 

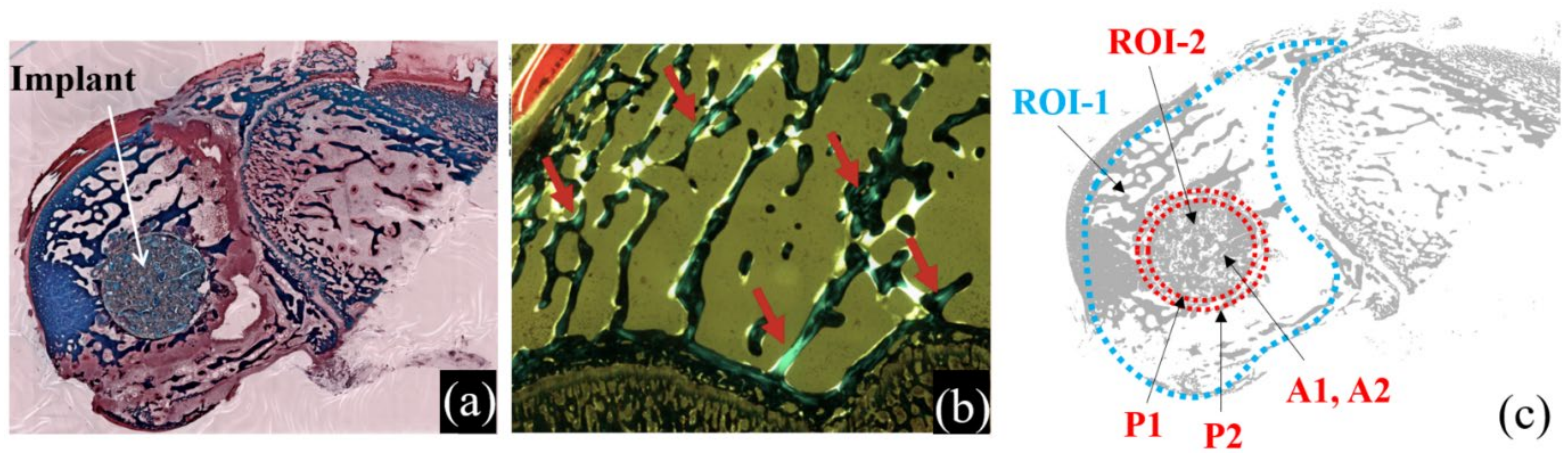

Figure 3. Representative examples of a) Masson's trichrome (MT) staining image of a bone condyle of a rabbit in the $M P C$ group, b) polarized light image in MT staining (corresponding to a sample in Empty Defect group) showing in bright green (arrows) the zones of trabecular bone with collagen fiber alignment, and c) definition of the regions of interest (ROI-1 and ROI-2) for histomorphometric quantification; P1: perimeter of the biomaterial; P2: dilatation of the perimeter P1; A1: bone area delimited by the internal perimeter P1; A2: bone area delimited by the dilated perimeter P2 (P1, P2, A1 and A2 are the parameters used to calculate the trabecular bone pattern factor, TBPf, as indicated in Equation 1).

For each region of interest the bone volume density (also called bone volume over total volume; $\mathrm{BV} / \mathrm{TV}$ ), the trabecular thickness (Tb.Th) and the trabecular bone pattern factor (TBPf) were evaluated using FiJi software ${ }^{25}$ and BoneJ plugin ${ }^{26}$, which are Java-based image processing programs developed at the National Institutes of Health and the Laboratory for Optical and Computational Instrumentation.

$\mathrm{BV} / \mathrm{TV}$ and $\mathrm{Tb}$.Th were evaluated following the methodology described by Schindelin et al. ${ }^{26}$ and Doube et al. ${ }^{25}$. To reduce variability in BV/TV and Tb.Th between animals, the values obtained for the implanted femur (ROI-2) were normalized by the respective value of the non-infected/nonimplanted contralateral femur (ROI-1) and the results were expressed as percentage of variation. The normalization transformed $\mathrm{BV} / \mathrm{TV}$ and $\mathrm{Tb}$.Th values to $\sim 0 \%$ if the implanted femur had similar properties than the contralateral femur (healthy bone) or negative values in case that the BV/TV and Tb.Th were reduced due to the infection process.

The trabecular connectivity was evaluated measuring the TBPf according to indirect bidimensional methods ${ }^{27}$. Briefly, trabecular bone area (A1) and perimeter (P1) were measured delineating the edges of the implanted biomaterial. Using an automatic image analysis system, a concentric bigger circle was drawn, and trabecular bone area (A2) and perimeter (P2) were measured again (Figure 3c). TBPf is defined as a quotient of the difference of the first and the second measurement ${ }^{27}$ :

$$
\mathrm{TBPf}=(\mathrm{P} 1-\mathrm{P} 2) /(\mathrm{A} 1-\mathrm{A} 2) \quad \text { Equation } 1
$$

In the bigger circle, bone area always increases without regard of the curvature. However, bone perimeter only increases in convex surfaces. Trabecular bone with many concave structures (healthy) 
shows a negative TBPf. In contrast, many convex structures (osteopenia/osteoporosis) produces a positive value ${ }^{27}$.

To integrate these parameters in the overall score, the BV/TV, Tb.Th and TBPf values were normalized to a scale from 0 to 4 (according with Table 2).

2.4.4. Bone regenerative process and bone infection evaluation. The collagen orientation in new, growing bone was observed with MT stained samples under polarized light (Figure 3b). Brighter areas showed oriented collagen fibers. In addition, the inflammatory infiltrate, bone sequestrum, revascularization, active bone cells and organization of the fibrous tissue were evaluated with HE images acquired randomly in four different frames of each femoral condyle sample. These semiquantitative evaluations were performed by two independent experts using a scale from 0 to 4 according with Table 2. 
Table 2. Description and scoring criteria of the semi-quantitative parameters evaluated to determine the degree of bone infection, bone structural integrity and regenerative process in scale from 0 to 4 .

\begin{tabular}{|c|c|c|c|}
\hline Category & Parameter & Description & Semi-quantitative score \\
\hline \multirow{5}{*}{$\begin{array}{l}\text { Bone } \\
\text { infection }\end{array}$} & $\begin{array}{l}\text { Systemic monocyte } \\
\text { counts }\end{array}$ & $\begin{array}{l}\text { Monocyte density determined } \\
\text { by blood test }\end{array}$ & $\begin{array}{l}0: \text { maximum monocyte density } \\
\text { 4: minimum monocyte density }\end{array}$ \\
\hline & $\begin{array}{l}\text { Albumin/globulin } \\
\text { (A/G) ratio }\end{array}$ & $\begin{array}{l}\text { Plasma protein concentration } \\
\text { determined by blood test }\end{array}$ & $\begin{array}{l}\text { 0: minimum } \mathrm{A} / \mathrm{G} \text { ratio } \\
\text { 4: maximum } \mathrm{A} / \mathrm{G} \text { ratio }\end{array}$ \\
\hline & $\begin{array}{l}\text { Inflammatory } \\
\text { infiltrate }\end{array}$ & $\begin{array}{l}\text { Frequency of monocytes in } \mathrm{HE} \\
\text { staining }\end{array}$ & $\begin{array}{l}\text { 0: monocytes observed in the four images } \\
\text { 4: no monocytes observed in any of the four images }\end{array}$ \\
\hline & Fibrosis & $\begin{array}{l}\text { Amount of fibrotic tissue in } \\
\text { HE staining }\end{array}$ & $\begin{array}{l}\text { 0: fibrotic tissue observed in the four images } \\
\text { 4: no fibrotic tissue observed in any of the four } \\
\text { images }\end{array}$ \\
\hline & Bone sequestrum & $\begin{array}{l}\text { Bone trabeculae isolated by } \\
\text { inflammatory infiltrate in } \mathrm{HE} \\
\text { staining }\end{array}$ & $\begin{array}{l}\text { 0: sequestrum observed in the four images } \\
\text { 4: no sequestrum was observed in any of the four } \\
\text { images }\end{array}$ \\
\hline \multirow{4}{*}{$\begin{array}{l}\text { Bone } \\
\text { structural } \\
\text { integrity }\end{array}$} & Bone density & $\begin{array}{l}\text { Radiographic evaluation of } \\
\text { bone lesion }\end{array}$ & $\begin{array}{l}\text { 0: severe sequestrum formation and/or bone } \\
\text { destruction } \\
\text { 4: no signs of sequestrum or bone destruction }\end{array}$ \\
\hline & $\begin{array}{l}\text { Bone volume density } \\
(\mathrm{BV} / \mathrm{TV})\end{array}$ & $\begin{array}{l}\text { Bone volume over total } \\
\text { volume in MT staining }\end{array}$ & $\begin{array}{l}\text { 0: minimum BV/TV (negative values) } \\
\text { 4: maximum BV/TV ( } \sim 0 \text { or positive values })\end{array}$ \\
\hline & $\begin{array}{l}\text { Trabecular thickness } \\
\text { (Tb.Th) }\end{array}$ & $\begin{array}{l}\text { Thickness of the trabecular } \\
\text { bone in MT staining }\end{array}$ & $\begin{array}{l}\text { 0: minimum Tb.Th (negative values) } \\
\text { 4: maximum Tb.Th }(\sim 0 \text { or positive values) }\end{array}$ \\
\hline & $\begin{array}{l}\text { Trabecular bone } \\
\text { pattern factor (TBPf) }\end{array}$ & $\begin{array}{l}\text { Connectivity of the trabecular } \\
\text { bone in MT staining }\end{array}$ & $\begin{array}{l}\text { 0: maximum TBPf (positive values) } \\
\text { 4: minimum TBPf (negative values) }\end{array}$ \\
\hline \multirow{4}{*}{$\begin{array}{l}\text { Bone } \\
\text { regeneration }\end{array}$} & Revascularization & $\begin{array}{l}\text { Presence of blood vessels in } \\
\text { HE staining }\end{array}$ & $\begin{array}{l}0 \text { : absence of blood vessels in the four images } \\
\text { 4: presence of blood vessels in the four images }\end{array}$ \\
\hline & Cellular activity & $\begin{array}{l}\text { Presence of osteoblasts, } \\
\text { osteocytes and/or osteoclasts } \\
\text { in HE staining }\end{array}$ & $\begin{array}{l}0: \text { absence of bone cells in the four images } \\
\text { 4: presence of bone cells in the four images }\end{array}$ \\
\hline & $\begin{array}{l}\text { Organization } \\
\text { fibrous tissue }\end{array}$ & $\begin{array}{l}\text { Alignment of the fibers in the } \\
\text { inflammatory infiltrate in HE } \\
\text { staining }\end{array}$ & $\begin{array}{l}\text { 0: no signals of alignment in any of the four images } \\
\text { 4: fibers oriented in a preferential direction in the } \\
\text { four images }\end{array}$ \\
\hline & $\begin{array}{l}\text { Collagen orientation } \\
\text { in new growing bone }\end{array}$ & $\begin{array}{l}\text { Alignment of collagen fibers } \\
\text { observed in MT staining under } \\
\text { polarized light }\end{array}$ & $\begin{array}{l}\text { 0: no signals of alignment in any of the four images } \\
\text { 4: collagen oriented in a preferential direction in the } \\
\text { four images }\end{array}$ \\
\hline
\end{tabular}




\subsection{Evaluation of the efficacy of the treatment}

An extensive evaluation of the health state of the animals using a composite score was performed, considering three different categories: 1) infection, 2) bone structural integrity and 3) regenerative processes (Figure 4). The value of each category was scored between 0 and 4 as described below, using the parameters evaluated according with Table 2 .

2.5.1 Infection score. Calculated as average of systemic (monocyte counts and albumin/globulin ratio evaluated by blood test) and local (inflammatory infiltrate, fibrosis and presence of sequestrum evaluated by HE staining) parameters. The score was normalized to a 0 to 4 scale, being 0 severe signs of infection and 4 no signs of infection (Table 2).

2.5.2 Bone structural integrity score. Calculated as the average of the three histomorphometric parameters evaluated from MT staining (BV/TV, Tb.Th and TBPf) and the bone density evaluated radiographically. The numerical values were all normalized to a 0 to 4 scale, 4 indicating high structural integrity (Table 2).

2.5.3 Regenerative processes score. Calculated as the average of the following four histomorphometric parameters: revascularization, presence of active bone cells, organization in fibrous tissue and collagen orientation in new growing bone. A scale between 0 and 4 was used, 4 indicating signs of important and active regenerative actions (Table 2).

2.5.4 Calculation of the health state composite score. The composite score, which indicated the overall health state of animals, was calculated using Equation 2.

Health State Composite Score $=$ Infection score + Bone structural integrity score + Regenerative process score (Equation 2)

Therefore the composite health score ranges from 0 (poor health state as consequence of the infection) to 12 (good animal health state). 

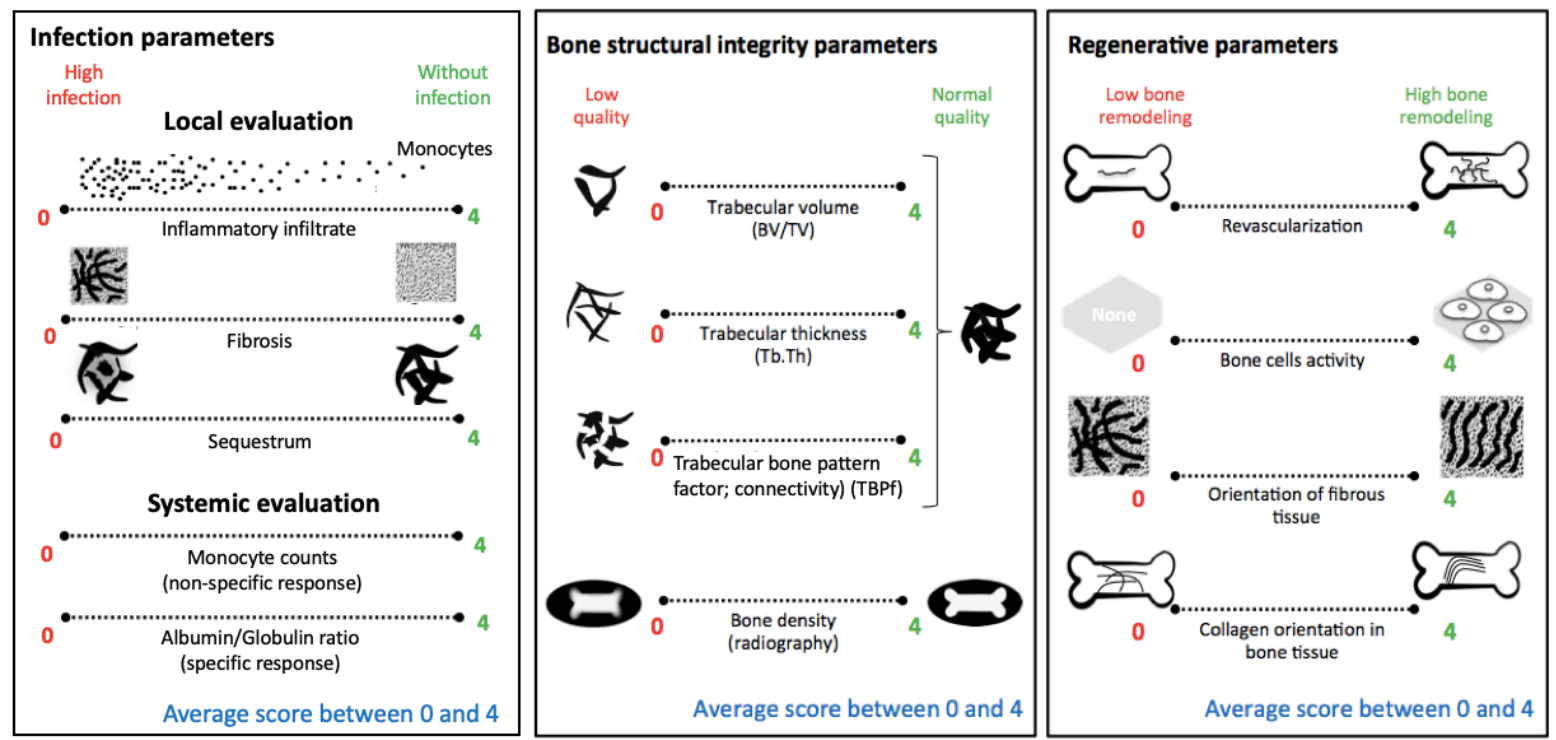

Figure 4. Schematic representation of the three categories considered to calculate the animal health state composite score according to Equation 2. Each category includes the parameters evaluated to calculate its value and the meaning of the minimum and maximum scores. Each parameter or category was scored between 0 and 4 according to Table 2 .

\subsection{Statistical analysis}

Data was statistically analysed by applying one-factor ANOVA test. In the case of composite scores, a maximum of 2 outliers were removed before applying one-factor ANOVA test. Significant differences between groups were determined by Tukey analysis. Statistical significance was considered when $p<0.05$ and data are presented as mean \pm standard deviation. Statistical analysis was performed using Minitab 16 software (Minitab, Inc., USA).

\section{Results}

All animals survived the entire assay, being sacrificed at 7 or 28 days as planned. All animals presented an antalgic posture of the operated limb and a reduction of food intake. Two rabbits out of six of the Empty defect group presented ataxia and diarrhoea.

\subsection{Systemic evaluation of the osteomyelitis state}

Blood testing was performed before surgery (day 0), 7 days after infection (day 7) and after the bone grafting treatments (day 28). Figure $5 \mathrm{a}$ and $5 \mathrm{~b}$ shows the monocyte counts and albumin/globulin ratio (A/G ratio), respectively. A statistically significant increase in monocyte counts was observed between Healthy group (day 0) and Infection-7d group, along with a statistically significant decrease in the $\mathrm{A} / \mathrm{G}$ ratio. In contrast, the monocyte counts and the $\mathrm{A} / \mathrm{G}$ ratio did not significantly change over time (between day 7 and day 28) regardless of the treatment used. 
a)

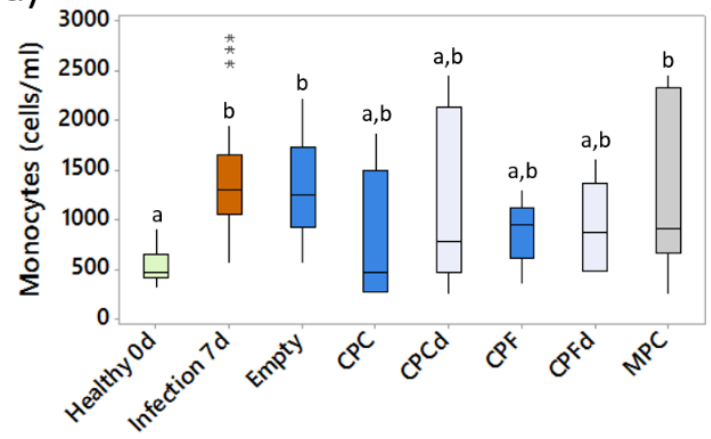

b)

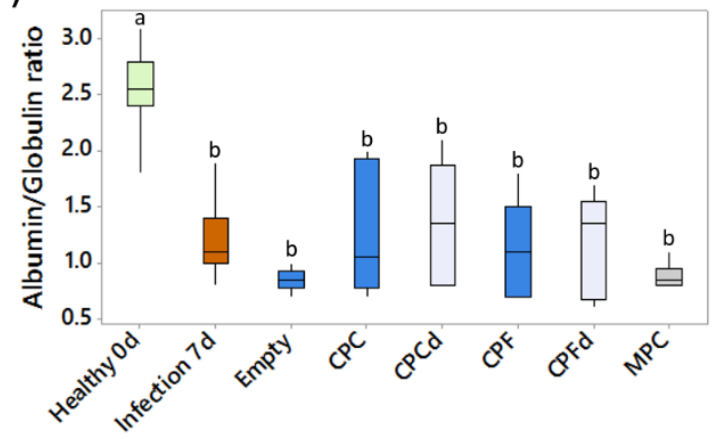

Figure 5. Summary of blood test results: a) Monocyte density and b) albumin/globulin ratio (values not yet normalized). Same letters indicate no statistically significant differences between groups $(p>0.05)$.

\subsection{Local evaluation of bone infection and bone regenerative process}

Figure 6 shows representative HE staining images that exemplify the phenomena used to score the bone infection and the bone regenerative process.

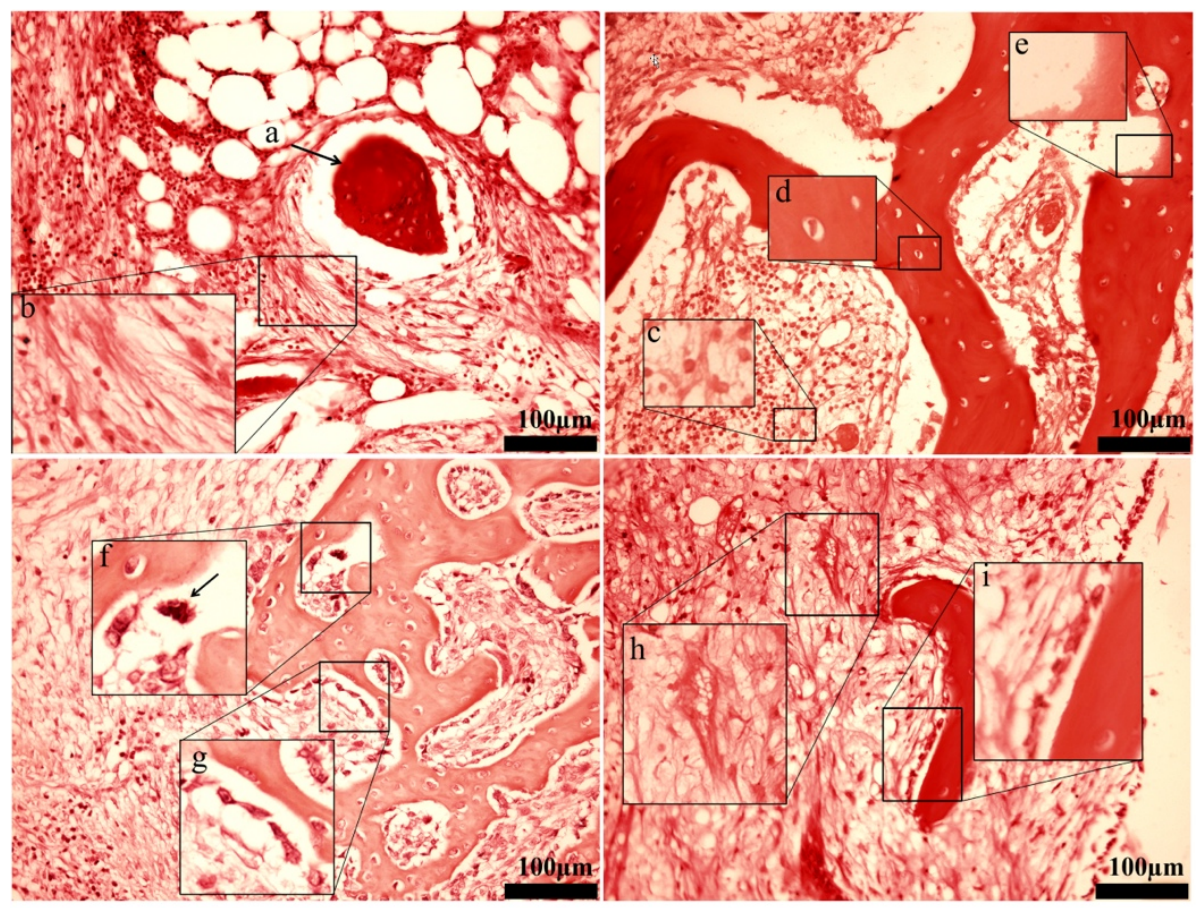

Figure 6. Representative Haematoxylin-Eosin stained optical microscope images of different samples implanted in the femoral condyle of rabbits showing: a) encapsulation of a trabecula and b) alignment of the fibers in the inflammatory infiltrate (Empty defect sample; upper left image); c) monocytes in the inflammatory infiltrate, d) osteocytes and e) osteoclastic (Howship's) lacuna (CPC sample, upper right image); f) active osteoclast and g) osteoblasts ( $C P F$ sample; lower left); h) one blood vessel and i) active osteoblasts (CPFd sample; lower right).

Figure 7 summarizes the result of both bone infection and regenerative process categories, which were scored in a 0 to 4 scale (see Table 2). A value of 0 indicates no signals of infection or of 
regenerative process, whereas a value of 4 indicates high signals of infection or of regenerative process (see Figure 4).
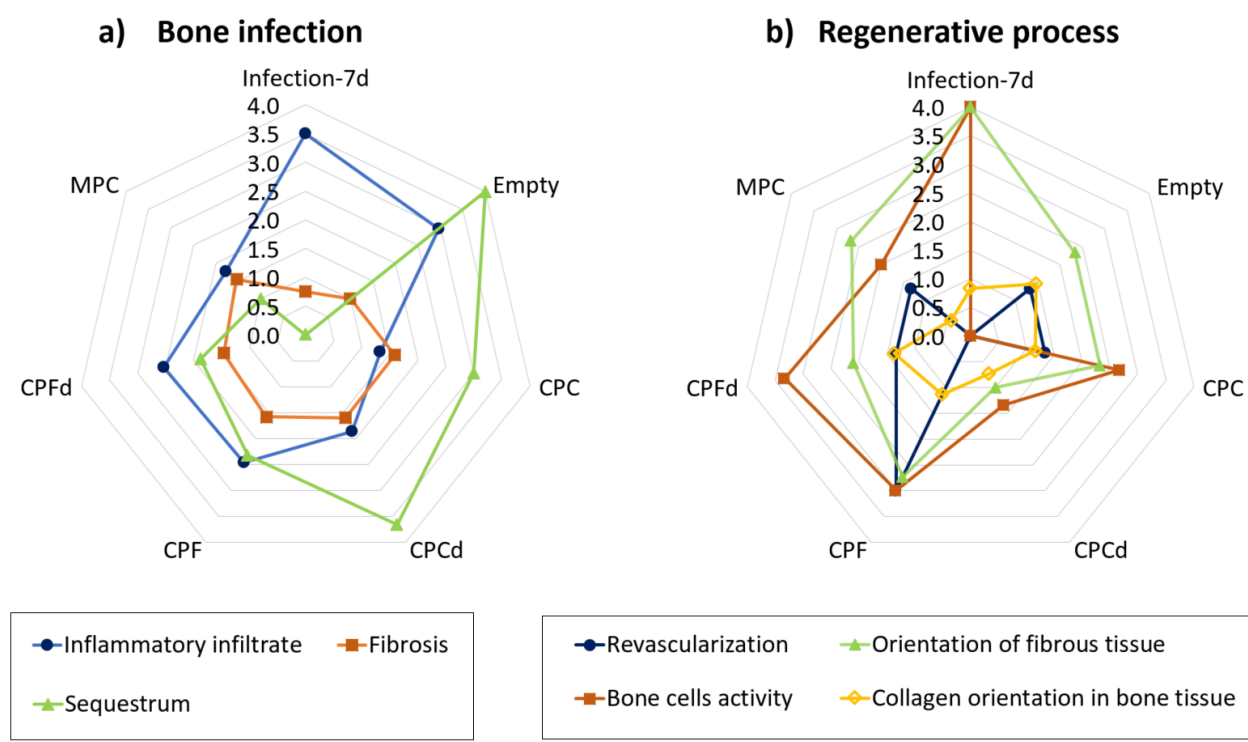

Figure 7. Scores of the parameters categorized: a) local bone infection (inflammatory infiltrate, fibrosis and sequestrum), and b) regenerative process (revascularization, bone cells activity, orientation of fibrous tissue and collagen orientation in bone tissue). The parameters were evaluated on Haematoxylin-Eosin staining images in accordance with Table 2. A value of 0 (centre of the graph) indicates high infection/ no signs of regenerative process, while a value of 4 (periphery of the graph) indicates no signs of infection/high signs of regenerative process. Error bars and significant statistical differences between groups were not included for clarity of the results.

The results from the bone infection category are described below. Infection-7d showed the highest values of fibrosis (i.e. amount of fibrotic tissue) and bone sequestrum (i.e. a bone trabecula isolated by inflammatory cells). This indicates that 7 days after infection the animals were under a severe osteomyelitis. Unexpectedly, low signs of inflammatory infiltrate (i.e. amount of monocytes) were observed for the Infection-7d and the Empty group. Fibrosis was observed in all groups to a similar extent (no statistically significant differences). Infection-7d and MPC groups showed statistically significant higher signals of bone sequestrum than Empty and $C P C d$ groups. The non-infected/nonimplanted contralateral femur did not show signs of bone infection along the entire experiment (data not shown).

The results from the bone regenerative process category are described below. Revascularization and collagen orientation were the least frequently observed signals of bone regeneration in the osteomyelitis site. Most groups presented values equal or below 1.5 for these two parameters and only the $C P F$ group showed higher signals of revascularization with a score equal to 3 (significantly different 
to Infection-7d and $C P C d$ groups). The orientation of fibrous tissue within the new growing bone did not show differences between groups. Surprisingly, the orientation of fibrous tissue and bone cell activity were maximum for Infection-7d group. After 28 days, although systemic or local treatments were applied, both orientation of collagen and bone cell activity were reduced indicating a lower degree of bone regeneration.

\subsection{Local evaluation of bone structural integrity}

The trabecular volume (BV/TV) variation and the Trabecular Thickness (Tb.Th) variation are summarized in Figure 8a and b, respectively. The variation in each parameter at the ROI-2 was calculated against the ROI-1 of the non-infected/non-implanted contralateral femur. Therefore, a similar degree of $\mathrm{BV} / \mathrm{TV}$ and $\mathrm{Tb}$. Th in the implanted bone compared to the contralateral femur would give a variation value close to $0 \%$. Negative values indicate a decrement of the parameter in the implanted area (ROI-2) respect to the contralateral femur (ROI-1).

The Infection- $7 d$ group presented a median value of BV/TV variation around $-20 \%$ with an important dispersion (Figure 8a). The decrease in trabecular volume in the infected/implanted femurs, which was rather heterogeneous between animals, could be associated with local osteomyelitis. After the treatment, the Empty, $C P C d$ and $C P F$ groups showed the most negative BV/TV median values (around -60\%), indicating more local bone destruction. In contrast, $C P F d$ and $M P C$ groups kept BV/TV median values similar to Infection-7 $d$ group, indicating the arrest of bone destruction, and were the only groups that presented statistical significant differences with $C P C d$ group, which showed the lowest $\mathrm{BV} / \mathrm{TV}$ value.

The decrease in trabecular thickness (Tb.Th variation, Figure $8 \mathrm{~b}$ ) was smaller for the Empty, $C P F, C P F d$ and $M P C$ groups (Tb.Th between -10 and $-20 \%$ ) than for Infection-7d, CPC and CPCd groups (Tb.Th between -40 and $-60 \%$ ). This indicates that Infection-7d, CPC and CPCd groups had the most significant decrease in trabecular thickness, which can be ascribed to a more severe osteomyelitis process. This decrease in trabecular thickness was however only statistically significantly different for the $C P C d$ group respect to Empty, $C P F, C P F d$ and $M P C$ groups.

The decrease of trabecular thickness was more important than the decrement of trabecular volume for half of the groups (Infection-7d, CPC and CPCd), whereas a similar percentage was obtained for the other groups.

Similar results were observed for the trabecular bone pattern factor (TBPf) variation (Figure 8c). On the one hand, the Empty, $C P F$ and $C P F d$ groups showed positive TBPf median values, indicating a loss of trabecular connectivity. On the other hand, the Infection-7d, $C P C, C P C d$ and $M P C$ groups showed negative TBPf median values, revealing a healthy trabecular connectivity. No significant differences were observed between treatments.

The results of bone density (Figure $8 \mathrm{~d}$ ) by radiographic analysis according to Table 2 did not show any sign of bone mass loss (normal bone density considered as 4) for the Infection-7d group. At 
28 days, all treatment groups showed significant reduction of bone density respect Infection-7d group. Most groups showed a bone density around 2, except $C P C$ group showing the lowest bone density.

a)

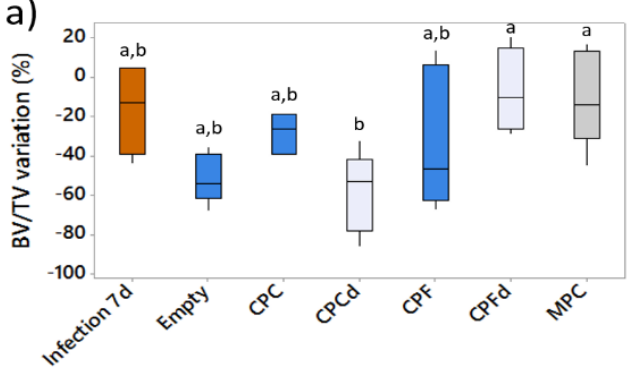

c)

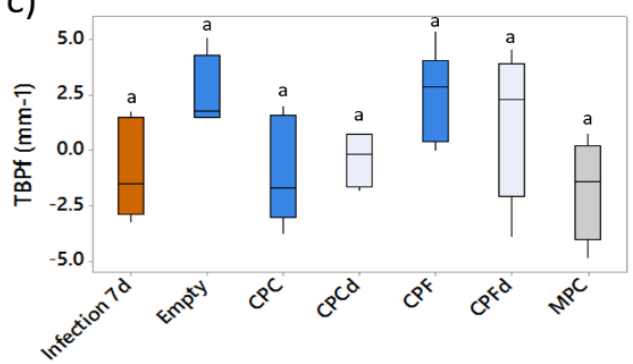

b)

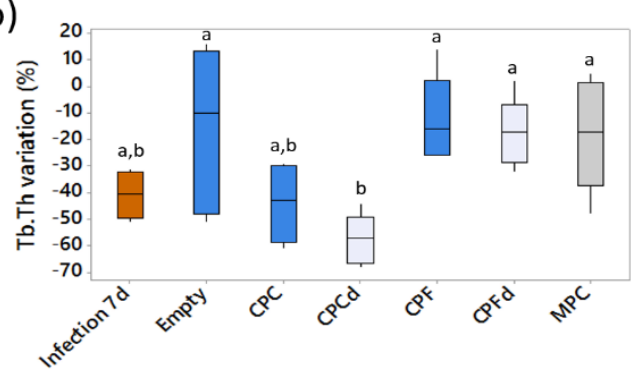

d)

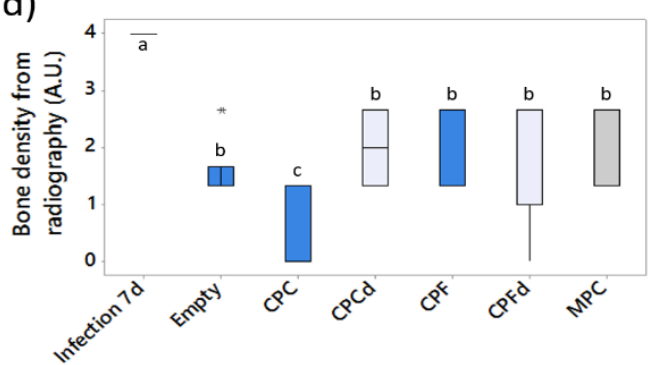

Figure 8. Histomorphometry results including a) bone volume density (BV/TV) variation and b) trabecular thickness (Tb.Th) variation between ROI-2 (implanted femur) and ROI-1 (non-infected/non-implanted contralateral femur, c) trabecular bone pattern factor (TBPf) representing the connectivity of the trabeculae in ROI-2, and d) radiographic semi-quantification of bone density ( 0 representing low and 4 representing normal bone mass). For BV/TV and $\mathrm{Tb}$. Th a value close to zero indicates high trabecular volume and high trabecular thickness, respectively. For TBPf, a negative value indicates a healthy architecture of the trabeculae. For bone density, a higher number indicates a higher bone density. Same letters indicate no statistical differences between groups $(p>0.05)$.

\subsection{Global outcome of the efficacy of the treatments against osteomyelitis}

The results of systemic infection (Figure 5, non-normalized data), local infection and regenerative process (Figure 7, normalized data within 0-4 scale), and bone structure (Figure 8, nonnormalized data) were pulled together to create Figure 9, which shows the scores obtained for each category (infection, bone structural integrity and regenerative process) as well as the health state composite score. The value for each category was calculated as the average of the parameters included according to Table 2 and Figure 4. The most relevant differences between groups within categories are indicated below. None of the treatments showed any statistical significant differences regarding the category infection. Regarding bone structural integrity, the best results were shown for Infection- $7 d$ and $M P C$ groups, whereas Empty, $C P C$ and $C P C d$ groups showed the worst outcome. Regarding the bone regeneration process, best results were shown for $C P F, C P F d$ and $M P C$ groups, whereas Infection- $7 d$, Empty, $C P C$ and $C P C d$ groups showed the poorest bone regeneration. 
The three categories independently evaluated were added up according to Equation 2 to get an overall and comprehensive evaluation of the efficacy of the treatments to eradicate osteomyelitis. A low value of the composite score indicates a severe osteomyelitis. Infection-7d group showed the worst health state (with a value of 4.7 out of 12). This score confirmed the presence of severe osteomyelitis after the infection period. After 28 days of treatment, the Empty, CPC and $C P C d$ groups showed a very similar composite score (between 4.2 and 4.7) than the Infection- $7 d$ group. In contrast, $C P F, C P F d$ and $M P C$ groups presented a statistically significant higher composite score (between 6.1 and 6.4), showing signs of improvement of the health state.

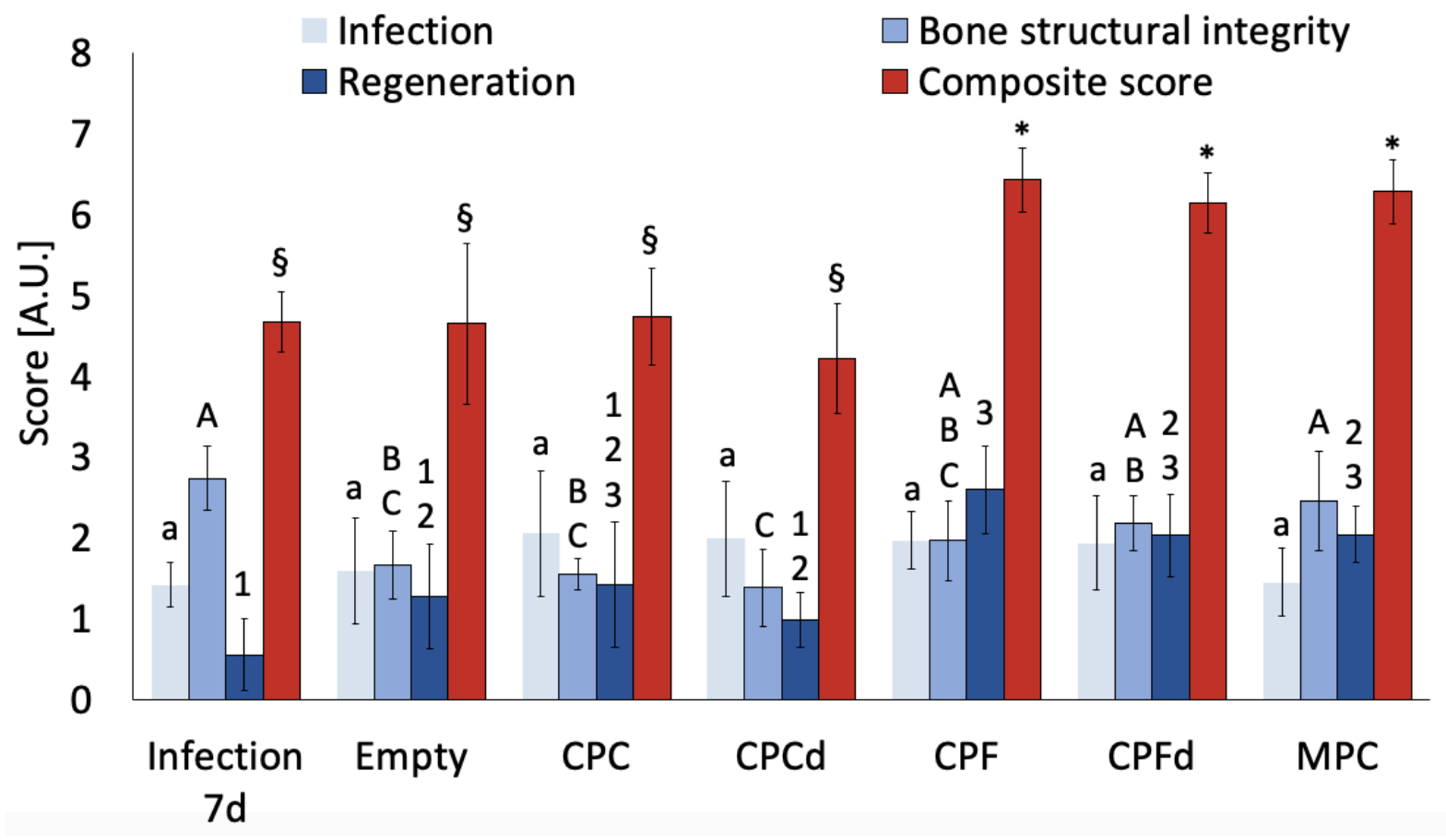

Figure 9. Scores for the categories evaluated separately (infection, bone structural integrity and regenerative process) and the health state composite score quantified following Equation 2. Regarding the infection score, a low value indicates high bone infection, whereas a high value indicates low bone infection. For bone structural integrity and regenerative process, a low value indicates a poor bone structural integrity/regenerative process,

whereas a high value indicates a high bone structural integrity/regenerative process. For the health state composite score, a high value indicates a good health of the animal, whereas a low value indicates a poor health state. Statistics are indicated by minuscule letters (infection), majuscule letters (bone structural integrity), number (regeneration) and composite score (symbol). Same letters, numbers or symbols indicate no statistical differences between groups within the correspondent score $(p>0.05)$.

\section{Discussion}

A surgical procedure always involves a prophylaxis treatment to reduce the risk of infection, including a systemic perioperative therapy with antibiotics. Despite such precautions, osteomyelitis still represents around $1 \%$ of the outcome of an orthopaedic surgery ${ }^{28,29}$. The management of bone infections is one of the current challenges for healthcare systems. The type of treatment that must be 
employed to eradicate the osteomyelitis depends on the stage of bone infection, the individual and the specific pathogen ${ }^{30}$. The treatment usually involves a surgical procedure, with a debridement phase, in addition to the systemic and local antimicrobial therapy.

In the present work, an animal model for the creation and treatment of osteomyelitis was employed based on previous works ${ }^{1,31}$. The model consisted in causing a perioperative infection by placing a temporal implant coated with sessile bacteria in a femoral head defect of New Zealand rabbits. After 7 days of infection, the temporal implants used to generate osteomyelitis were replaced by antimicrobial, injectable and osteoconductive materials aiming to heal osteomyelitis. Surgical debridement and removal of the infected tissue were not performed, only pus was aspired. The infection created was extensive, so the biomaterials faced a challenging scenario.

Osteomyelitis perturbs local homeostasis, triggering a cascade of inflammatory response and wound healing. Initially, an acute inflammation causes an increase of inflammatory cells (monocytes and neutrophils) in the systemic circulation, which reach the infected site. On site, monocytes differentiate into macrophages, which together with neutrophils release oxidative species and cytokines. Cytokines are chemical messengers that recruit even more inflammatory cells to fight the infection and endothelial cells to quickly synthesize fibrous tissue at the infection site. Macrophages also phagocytize dead cells and tissue/material debris. If the acute inflammation does not fade away, the cellular events change after few days, the condition being then named chronic inflammation. Prolonged inflammation is detrimental for the affected site, since high level of oxidation damages healthy cells and tissue, while at the same time bone remodelling processes are hindered ${ }^{32}$. In an ideal scenario, a local and/or systemic treatment together with the immune system can overcome the osteomyelitis. After this period, inflammatory cells migrate back and the tissue recovers its physiological balance. In the case of osteomyelitis in New Zealand rabbits, the amount of systemic monocytes should decrease after $\sim 28$ days $^{31}$, if the treatment applied is effective enough compared to the extent of the infection. Once the normality of the tissue is restored, several more weeks are needed to be able to observe the results of bone remodelling, which synthesizes new bone with the adequate trabecular architecture and irrigated with blood vessels created by angiogenesis ${ }^{33}$.

The severity of osteomyelitis may be defined by systemic and/or local evaluations ${ }^{4}$. Its clinic diagnostic is commonly limited to the least invasive methods available, i.e. radiography and blood tests. An approach to evaluate bone osteomyelitis in a rabbit model was previously proposed by Smeltzer $e t$ $a l .^{23}$. The main limitation of Smeltzer's evaluation is that it only evaluates bone destruction parameters. The present work provides a more comprehensive composite score to determine variations in the health state of the animals caused by the osteomyelitis and the therapies used to eradicate it. This new composite score considers three different categories: bone infection, bone structural integrity and bone regeneration (Figure 4). The present study shows that the proposed composite score allows the assessment of statistically significant differences between antimicrobial therapies, which the individual parameters were not able to discern. 
The Infection-7d group showed clear signs of systemic infection (high count of monocytes and low counts of albumin/globulin ratio) (Figure 5) and of local infection (high sequestrum) (Figure 7a). However, the inflammatory infiltrate observed was low (Figure 7a), the fibrous tissue was oriented and bone cell activity was observed (Figure $7 \mathrm{~b}$ ). In addition to that, a slightly negative BV/TV (-10\%) and a negative TBPf $(-2.5 \mathrm{~mm}$ ) (Figure $8 \mathrm{a}$ and $\mathrm{c}$ ) was determined, indicating that the bone volume and thickness had been only slightly affected, respectively. In accordance to that, the bone density observed by radiographies did not show signs of infection at 7 days (Figure $8 d$ ). This could indicate that at 7 days the bone properties were still not affected by the osteomyelitis process. With time, the analysed parameters showed that the therapies applied were successful to arrest bone infection and improve bone regeneration. However, none of the treatments were effective to significantly enhance bone structural integrity by slowing or stopping the deterioration of the trabecular volume and thickness with time (Figure 9). This evidences that one of the limitations of this study is that the evaluation was only done at two time points ( 7 and 28 days), thus missing the time course evolution of the infection. It can be speculated that a longer evaluation time would have been crucial to detect an improvement of the bone structure. Evaluating only two time points was decided for ethical reasons, to reduce the number of animals.

While MPC presents intrinsic antimicrobial activity ${ }^{21}$, CPC and CPF require the incorporation of an antimicrobial agent, in this case doxycycline hyclate, to present antimicrobial character ${ }^{17}$. Therefore, the animal study was designed to evaluate the effectiveness of different treatments to eradicate the bone infection focusing on 1) the method of antibiotic administration (systemic for Empty defect, $C P C$ and $C P F$ groups vs. local for CPCd and CPFd), 2) the type of antimicrobial agent (local release of doxycycline hyclate for CPCd and CPFd vs. intrinsic antimicrobial MPC) and 3) the porosity of the local antimicrobial carrier. In general, the global evaluation of osteomyelitis showed that macroporous CDHA ( $C P F$ and $C P F d$ ) and microporous $M P C$ allowed a better containment of the osteomyelitis condition (Figure 9). Nonetheless, none of the treatments evaluated completely eradicated the induced bone infection. This was ascribed to the severity and extension of the infection created, which extended to the surrounding soft tissues instead of being limited to a local bone area, as previously observed in similar models ${ }^{34,35}$.

\subsection{The method of antibiotic administration (local vs. systemic)}

The health state composite score (Figure 9) does not show significant statistical differences between the methods of antibiotic administration (CPC vs CPCd and CPF vs CPFd). This means that under the conditions of this study, the local and systemic administration of doxycycline hyclate were equally effective to counteract the infection. Therefore, despite the short half-life of doxycycline hyclate (less than 2 days at $37^{\circ} \mathrm{C}^{36}$ ), it could be speculated that the carriers (both CPCd and CPFd) protected the antibiotic from degradation and its antimicrobial activity was kept at a similar level than the daily renewal of systemic antibiotic administration. 
A previous work showed that CPF specimens loaded with $50 \mathrm{mg}$ of doxycycline hyclate (same amount as in the current work) released around $1 \mathrm{mg}$ of doxycycline hyclate after $100 \mathrm{~h}^{17}$. This amount that would be released locally at the infection site was only 20 times lower than the typical systemic dose used in rabbits (20 $\mathrm{mg}$ for a $5 \mathrm{~kg}$ rabbit), where the drug gets distributed along the body and has to overcome several body barriers to reach the infected site.

Nevertheless, it should be considered that the region of action of the local administrated antibiotic is limited to the surroundings of the implant, making the bone defect susceptible to reinfection if the local concentration of antibiotic decreases below its therapeutic window. Therefore, for optimal screening of antimicrobial therapies, a more controlled method to produce the bone infection without spreading to other tissues is still required.

\subsection{The type of local antimicrobial agent (release of doxycycline hyclate vs. intrinsic antimicrobial} activity of MPCs)

CPCs and MPCs have similar intrinsic porosity in the range of $0.006-0.1 \mathrm{~mm}$ for $\mathrm{CPCs}^{19}$ and 0.006-70 $\mathrm{mm}$ for $\mathrm{MPCs}^{20}$ (Table 1). Therefore, the effectiveness of the type of local antimicrobial agent was tested comparing $C P C d$ and $M P C$ groups. The health state composite score (Figure 9) shows that the intrinsic antimicrobial properties of MPC were more effective to improve the health state of the animals than the doxycycline hyclate released by CPCd. In previous works, CPCs loaded with doxycycline hyclate released relatively low amounts of drug, about $5 \%$ in 4 days ${ }^{19}$. This low release is ascribed to the low accessibility of fluids to the bulk of the material due to the small size of the pores, hampering its diffusion. Therein, in our work the release of low amounts of antibiotic is expected from CPCs locally, explaining its lower efficiency with respect to MPC.

To the best of the author's knowledge, MPC demonstrated for the first time in vivo its intrinsic antimicrobial properties. The antimicrobial action of MPC was attributed to the local increase of $\mathrm{pH}$ $(0.85 \mathrm{~g} / \mathrm{ml}$ of MPC in PBS caused $\mathrm{pH} \sim 11)$ and the high osmolarity of the environment $(0.85 \mathrm{~g} / \mathrm{ml}$ of MPC in PBS caused $\sim 700 \mathrm{mOs} / \mathrm{Kg}$ after $72 \mathrm{~h})^{21}$. This antimicrobial activity, together with good biocompatibility and biodegradability ${ }^{37,38}$, make MPC a promising material for bone grafting and prophylaxis against bone infections.

\subsection{The porosity of the local antimicrobial carrier (microporous i.e. CPC vs. macroporous i.e. CPF)}

CPCs have intrinsic microporosity with pores smaller than $2 \mu \mathrm{m}^{19}$, whereas CPFs present a superimposed network of interconnected macropores (bigger than $5 \mu \mathrm{m}$ ) over the CPCs' intrinsic porosity ${ }^{17}$ (Table 1). The importance of the porosity was revealed by the composite score (Figure 9), which shows that the health state of the animals was better when they were treated with macroporous materials (CPF and CPFd) than with only microporous materials (CPC and CPCd). The better performance of doxycycline hyclate-loaded macroporous CDHA (CPFd) in comparison with the doxycycline hyclate-loaded microporous CDHA (CPCd) can be easily linked to the higher release of 
doxycycline hyclate (up to 13 times more) ${ }^{17}$. The higher dose of antibiotic could substantially decrease the infection and therefore explain the better activity in the osteomyelitic animals evaluated.

The better performance of pristine macroporous CDHA (CPF; antibiotic provided systemically) compared to the pristine microporous CDHA (CPC) can be assigned to their ability to preserve the bone structure integrity (i.e. healthy trabecular architecture) and enhance bone regeneration ${ }^{39}$. This can be ascribed to the better fluid exchange in the macroporous materials, allowing immune cells to penetrate into the scaffold and therefore increase their chances to contend the infection. Specifically, CPFs showed double scoring in bone regeneration than the empty defect or only microporous CPCs. This result correlated well with previous works in which CPFs were implanted in the femur condyle of New Zealand rabbits and good osteoconductive properties were observed, the CPFs being gradually replaced by bone while CPCs were not degraded ${ }^{18,40,41}$. Therefore, it can be concluded that macroporosity in CPF allows for better fluid exchange, which promotes bone cells activity, vascularization and better distribution of the antibiotic (either systemically or locally administrated) that synergistically counterbalance the destruction of bone.

In comparison with biodegradable polymeric carriers of antibiotics ${ }^{7}$, the biodegradable materials tested in this study have the advantage to be injectable, bioactive and osteoconductive. Therefore, these materials offer the possibility to be implanted via minimally invasive surgery and can promote the growing of new bone in parallel to the resorption of the implant, leading to the regeneration of bone tissue $e^{42}$. In comparison with other biodegradable and injectable inorganic cements used as antimicrobial carriers i.e. gypsum ${ }^{43}$, the resorption rate of calcium phosphates better matches the bone regeneration rate $^{42}$, turning them into a better alternative.

\section{Conclusions}

The multifactorial score proposed in this work provides an extended evaluation of the health state of the animals, considering factors grouped in three different categories, i.e. bone infection, bone structural integrity and bone regeneration. These categories are not considered in traditional osteomyelitis evaluation scores. The new composite scale developed in this work allows to discern statistically significant differences between antimicrobial therapies used to eradicate osteomyelitis state of the animals, which the individual categories were not enable to discern. It is therefore useful to evaluate in vivo the efficacy of biomaterials for bone regeneration with local antibiotic releasing properties. Under the present study conditions, local or systemic administration of doxycycline hyclate showed equivalent antimicrobial performance. Macroporosity in bioceramics was confirmed to be a key parameter, as macroporous materials (with pores larger than $5 \mu \mathrm{m}$ ) showed better performance than microporous materials (with pores smaller than $5 \mu \mathrm{m}$ ). MPC (which does not contain drug itself) confirmed its intrinsic antimicrobial activity in vivo, showing similar performance than macroporous materials loaded with doxycycline hyclate (CPFd). The injectability and osteoconductivity, together 
with either the intrinsic antimicrobial activity of MPC or the possibility to use CPF as carrier for an antibiotic active principle, confirm these materials as promising candidates for minimal invasive bone grafting and prophylaxis against osteomyelitis. 


\section{Acknowledgements}

The authors would like to sincerely thank Fernando Muñoz (animal experimentation facility of the Universidad de Santiago de Compostela, Spain) for his invaluable help with the animal experiment; Joan Serret Salse (CERETOX, experimental toxicology and ecotoxicology unit of the Park Scientific of Barcelona, Spain) for his help with the preparation of decalcified samples for histology; and Emilio Rendon (agricultural and animal production Department, Universidad Autónoma Metropolitana unidad Xochimilco, Mexico) for his help with the interpretation of the results of the blood test. Authors acknowledge the Spanish Government for financial support through Project MAT201565601-R, co-funded by the EU through European Regional Development Funds, and Ramon y Cajal fellowship of CC. Support for the research of MPG was received through the "ICREA Academia" prize for excellence in research, funded by the Generalitat de Catalunya.

\section{Conflicts of interest}

There are no conflicts to declare. 


\section{References}

1 J. S. Moskowitz, M. R. Blaisse, R. E. Samuel, H.-P. Hsu, M. B. Harris, S. D. Martin, J. C. Lee, M. Spector and P. T. Hammond, Biomaterials, 2010, 31, 6019-30.

2 M. N. Gamaletsou, D. P. Kontoyiannis, N. V Sipsas, B. Moriyama, E. Alexander, E. Roilides, B. Brause and T. J. Walsh, Clin. Infect. Dis., 2012, 55, 1338-51.

3 M. Ribeiro, F. J. Monteiro and M. P. Ferraz, Biomatter, 2012, 2, 176-94.

4 W. Reizner, J. Hunter, N. O’Malley, R. Southgate, E. Schwarz and S. Kates, Eur. Cells Mater., 2014, 27, 196-212.

5 C. L. Romanò, M. Toscano, D. Romanò and L. Drago, J. Chemother., 2013, 25, 67-80.

6 J. A. Wright and S. P. Nair, Int. J. Med. Microbiol., 2010, 300, 193-204.

7 M. H. Xiong, Y. Bao, X. Z. Yang, Y. H. Zhu and J. Wang, Adv. Drug Deliv. Rev., 2014, 78, $63-76$.

8 U. Joosten, A. Joist, T. Frebel, B. Brandt, S. Diederichs and C. Von Eiff, Biomaterials, 2004, 25, 4287-4295.

9 H. W. Buchholz, R. A. Elson and K. Heinert, Clin. Orthop. Relat. Res., 1984, 96-108.

10 H. van de Belt, D. Neut, W. Schenk, J. R. van Horn, H. C. van der Mei and H. J. Busscher, Acta Orthop. Scand., 2000, 71, 625-629.

11 J. Geurts, J. J. Chris Arts and G. H. I. M. Walenkamp, Injury, 2011, 42 Suppl 2, S82-6.

12 M. A. McNally, J. O. Small, H. G. Tofighi and R. A. Mollan, Two-stage management of chronic osteomyelitis of the long bones. The Belfast technique., 1993, vol. 75.

13 J. D. Laredo and B. Hamze, Skeletal Radiol., 2004, 33, 493-505.

14 R. Z. LeGeros, Chem. Rev., 2008, 108, 4742-4753.

15 R. O'Hara, F. Buchanan and N. Dunne, Injectable calcium phosphate cements for spinal bone repair in Biomaterials for Bone Regeneration: Novel Techniques and Applications, Cambridge (UK), WoodHead P., 2014.

16 E. B. Montufar, T. Traykova, C. Gil, I. Harr, A. Almirall, A. Aguirre, E. Engel, J. A. Planell and M. P. Ginebra, Acta Biomater., 2010, 6, 876-85.

17 D. Pastorino, C. Canal and M. P. Ginebra, Acta Biomater., 2015, 12, 250-259.

18 S. Del Valle, N. Miño, F. Muñoz, A. González, J. A. Planell and M. P. Ginebra, J. Mater. Sci. Mater. Med., 2007, 18, 353-361.

19 C. Canal, D. Pastorino, G. Mestres, P. Schuler and M. P. Ginebra, Acta Biomater., 2013, 9, 8403-8412.

20 G. Mestres and M. P. Ginebra, Acta Biomater., 2011, 7, 1853-1861.

21 G. Mestres, M. Abdolhosseini, W. Bowles, S. H. Huang, C. Aparicio, S. U. Gorr and M. P. Ginebra, Acta Biomater., 2013, 9, 8384-8393.

22 Y. An, Q. Kang and C. Arciola, Int J Artif Organs, 2006, 29, 407-420.

23 M. S. Smeltzer, J. R. Thomas, S. G. Hickmon, R. a Skinner, C. L. Nelson, D. Griffith, T. R. 
Parr and R. P. Evans, J. Orthop. Res., 1997, 15, 414-21.

24 M. Varga, Textbook of Rabbit Medicine, Elsevier Health Sciences, 2nd Ed., 2013.

25 M. Doube, M. M. Kłosowski, I. Arganda-Carreras, F. P. Cordelières, R. P. Dougherty, J. S. Jackson, B. Schmid, J. R. Hutchinson and S. J. Shefelbine, Bone, 2010, 47, 1076-9. J. Schindelin, I. Arganda-Carreras, E. Frise, V. Kaynig, M. Longair, T. Pietzsch, S. Preibisch, C. Rueden, S. Saalfeld, B. Schmid, J. Y. Tinevez, D. J. White, V. Hartenstein, K. Eliceiri, P. Tomancak and A. Cardona, Nat. Methods, 2012, 9, 676-682.

S. M. Kurtz, E. Lau, J. Schmier, K. L. Ong, K. Zhao and J. Parvizi, J. Arthroplasty, 2008, 23, 984-991.

29 D. P. Lew and F. A. Waldvogel, Lancet (London, England), 364, 369-79.

30 J. H. Calhoun, M. M. Manring and M. Shirtliff, Semin. Plast. Surg., 2009, 23, 59-72.

31 U. Joosten, A. Joist, G. Gosheger, U. Liljenqvist, B. Brandt and C. von Eiff, Biomaterials, 2005, 26, 5251-8.

32 J. M. Anderson, Annu. Rev. Mater. Res, 2001, 31, 81-110.

33 D. J. Hadjidakis and I. I. Androulakis, Ann. N. Y. Acad. Sci., 2006, 1092, 385-396.

34 C. W. Norden, R. L. Myerowitz and E. Keleti, Br. J. exp. Path.

35 L. R. Crane, C. C. Kapdi, J. N. Wolfe, B. K. Silberberg and A. M. Lerner, Proc. Soc. Exp. Biol. Med., 1977, 156, 303-14.

36 L. Gutiérrez, L. Ocampo, F. Espinosa and H. Sumano, J. Vet. Pharmacol. Ther., 2014, 37, 8389.

37 F. Wu, J. Wei, H. Guo, F. Chen, H. Hong and C. Liu, Acta Biomater., 2008, 4, 1873-84.

38 J. Wei, J. Jia, F. Wu, S. Wei, H. Zhou, H. Zhang, J.-W. Shin and C. Liu, Biomaterials, 2010, 31, 1260-9.

39 A. Barba, A. Diez-Escudero, Y. Maazouz, K. Rappe, M. Espanol, E. B. Montufar, M. Bonany, J. M. Sadowska, J. Guillem-Marti, C. Öhman-Mägi, C. Persson, M. C. Manzanares, J. Franch and M. P. Ginebra, ACS Appl. Mater. Interfaces, 2017, 9, 41722-41736.

40 A. Gaudin, G. Amador Del Valle, A. Hamel, V. Le Mabecque, A. F. Miegeville, G. Potel, J. Caillon and C. Jacqueline, Lett. Appl. Microbiol., 2011, 52, 253-7.

41 A. Kovtun, M. J. Goeckelmann, A. A. Niclas, E. B. Montufar, M. P. Ginebra, J. A. Planell, M. Santin and A. Ignatius, Acta Biomater., 2015, 12, 242-249.

42 F. C. M. Driessens, J. A. Planell, M. Boltong, I. Khairoun and M. P. Ginebra, Proc. Inst. Mech. Eng. Part H J. Eng. Med., 1998, 212, 427-435.

43 L. Dahners and C. Funderburk, Clin. Orthop. Relat. Res., 1987, 278-282. 